\title{
Surgical Outcomes of Anterior Cervical Fusion Using Deminaralized Bone Matrix as Stand-Alone Graft Material: Single Arm, Pilot Study
}

\author{
Ho-Jung Chung, Jung-Woo Hur, Kyeong-Sik Ryu, Jin-Sung Kim, Ji-Hoon Seong \\ Department of Neurosurgery, Seoul St. Mary's Hospital, The Catholic University of Korea College of Medicine, Seoul, Korea
}

\begin{abstract}
Objective: To investigate the safety and efficacy of demineralized bone matrix (DBM) as a bone graft substitute for anterior cervical discectomy and fusion (ACDF) surgery.

Methods: Twenty consecutive patients treated with ACDF using stand-alone polyestheretherketone (PEEK) cages (Zero-P) with DBM (CGDBM100) were prospectively evaluated with a minimum of 6 months of follow-up. Radiologic efficacy was evaluated with a 6-point scoring method for osseous fusion using plain radiograph and computed tomogrpahy scans. Clinical efficacy was evaluated using the visual analogue scale (VAS), Owestry disability index (ODI), and short-form health questionnaire-36. The safety of the bone graft substitute was assessed with vital sign monitoring and a survey measuring complications at each follow-up visit. Results: There were significant improvements in VAS and ODI scores at a mean 6-month follow-up. Six months after surgery, solid fusion was achieved in all patients. Mean score on the 6-point scoring system was 5.1, and bony formation was found to score at least 4 points in all patients. There was no case with implant-related complications such as cage failure or migration, and no complications associated with the use of CGDBM100.

Conclusion: ACDF using CGDBM100 demonstrated good clinical and radiologic outcomes. The fusion rate was comparable with the published results of traditional ACDF. Therefore, the results of this study suggest that the use of a PEEK cage packed with DBM for ACDF is a safe and effective alternative to the gold standard of autologous iliac bone graft.
\end{abstract}

Key Words: Anterior cervical diskectomy and fusion $\cdot$ Polyestheretherketone cage $\cdot$ Demineralized bone matrix $\cdot$ Bone grafting

\section{INTRODUCTION}

Historically, autologous bone harvested from a patient's iliac crest has been used as a cervical interbody fusion material ${ }^{19,42)}$. Although high fusion rates have been reported with autogenous bone grafts, frequently reported donor-site morbidity associated with iliac crest harvesting, such as chronic donor site pain, infection, wound hematoma, and numbness due to nerve injury, affects patient satisfaction ${ }^{39}$. In addition, the quality of the autologous graft material can be a concern in patients with osteoporosis, metabolic disorders, neoplasia, chronic inflammatory diseases, or infections, and, therefore, surgeons have attempted to identify substitute bone graft materials ${ }^{54)}$.

Demineralized bone matrix (DBM) is made of bone that has been acid-treated to remove the mineralized portion while maintaining the organic matrix and various growth factors ${ }^{46}$.

- Received: June 6, 2016 • Revised: August 24, 2016

- Accepted: August 29, 2016

Corresponding Author: Jung-Woo Hur

Department of Neurosurgery, Seoul St. Mary's Hospital, The Catholic University of Korea College of Medicine, 222 Banpo-daero, Seocho-gu, Seoul 06591, Korea

Tel: +82-2-2258-6265, Fax: +82-2-594-4248

E-mail: neurotique79@gmail.com

$\otimes$ This is an open access article distributed under the terms of the Creative Commons Attribution Non-Commercial License (http://creativecommons.org/licenses/by-nc/4.0/) which permits unrestricted non-commercial use, distribution, and reproduction in any medium, provided the original work is properly cited.
DBM consists of collagen and other growth factors, such as bone morphogenic protein (BMP), which provides osteoinductivity. Unlike allograft bone, DBM produces no immunological rejection as the surface antigenic structures are destroyed during demineralization. However, the osteogenic capacity of the bone is also lost during processing ${ }^{50}$. Previously published studies have supported the use of DBM as a potential alternative option for bone grafting ${ }^{13,32,51)}$, but there is no clinical evidence to support its usage as a stand-alone graft material.

The purpose of this study was to investigate the safety and efficacy of a DBM alone as a bone graft substitute for cervical interbody fusion surgery.

\section{MATERIALS AND METHODS}

This pilot study was conducted from September 2012 to November 2013 in Seoul St. Mary's Hospital, The Catholic University of Korea. Twenty consecutive patients treated with ACDF using stand-alone polyestheretherketone (PEEK) cages (Zero-P, Depuy-Synthes Spine Inc., Raynham, MA, USA) with DBM (CGDBM100, CGBio Inc., Seongnam, Korea) at the single level were prospectively evaluated with a minimum of 6 months of follow-up (mean, 12.2 months). All patients included in the study were between 20 and 70 years of age, had single-level cervical degenerative disease, and were scheduled for ACDF surgery. Patients were excluded if acute frac- 
ture, infection, neoplastic disease, or systemic diseases such as Alzheimer disease or cerebrovascular stroke which can affect surgical outcomes were identified during preoperative evaluation. We received informed consent form all participants before surgery and permission for this study. The patients ranged in age from 29 to 68 years, with a mean age of 50 years, and the male-to-female ratio was 3:2. The affected level was $\mathrm{C}^{-}$ 4 in 1 patient, $\mathrm{C}^{-}-5$ in 7, C5-6 in 7, and $\mathrm{C6}^{-7}$ in 5. Patients' demographic data are shown in Table 1.

The surgical procedure was identical in all patients. A standard anterior cervical discectomy was performed using a rightsided approach by a single surgeon. After the completion of discectomy and decompression of neural structures under a microscope, end-plate preparation was done with curettage. An appropriately sized trial implant was then placed into the disk space to confirm the size, position, and height of the implant to be used. In patients with foraminal narrowing, the posterior half of the uncovertebral joint was removed with a high-speed burr under the microscope. A Zero-P cage was filled with CGDBM100 in putty form and inserted into the disc space under fluoroscopic guidance (Fig. 1). The height of the cage $(5,6$, or $7 \mathrm{~mm})$ was determined after considering the stability of overdistraction. No additional bone graft was inserted anterior or lateral to the cage. After removing the Caspar screw, screws in the stand-alone cage were inserted into the vertebral body in an oblique upward and downward fashion. All patients were reviewed at 1,3 , and 6 months postoperatively in order to evaluate the efficacy and safety of the procedure.

Radiologic efficacy was evaluated with a 6-point scoring method for osseous fusion at 1,3 , and 6 months postoperati-

Table 1. Patient demographics and intraoperative data

\begin{tabular}{lc}
\hline \hline Characteristic & Value \\
\hline Sex & \\
Male & $12(60)$ \\
Female & $8(40)$ \\
Age (yr) & $50.0 \pm 10.3$ \\
Body mass index $\left(\mathrm{kg} / \mathrm{m}^{2}\right)$ & $23.2 \pm 4.4$ \\
Preoperative symptoms & \\
$\quad$ Visual analogue scale & $6.3 \pm 1.1$ \\
$\quad$ Owestry disability index & $20.2 \pm 8.1$ \\
Duration of pain (mo) & $14.9 \pm 6.2$ \\
Symptomatic level & \\
$\quad$ C3-C4 & $1(5)$ \\
C4-C5 & $7(35)$ \\
C5-C6 & $7(35)$ \\
C6-C7 & $5(25)$ \\
Intraoperative blood loss (mL) & $41 \pm 23$ \\
Operating time (min) & $63 \pm 14$ \\
Length of hospital stay (day) & $3.4 \pm 0.5$ \\
\hline
\end{tabular}

Values are presented as number (\%) or mean \pm standard deviation. vely using plain radiograph and computed tomography (CT) scans $^{26}$ (Fig. 2). We considered a bridging bone between the cage and the adjacent endplate of the vertebral body on each of six surfaces (anterior, posterior, superior, inferior, and both lateral sides) as one indicator point. Bridging bone formation on more than three surfaces was considered to be solid fusion with stability. Formation of bridging bone was examined on 6 surfaces around the graft using axial, coronal, and sagittal CT images. Additionally, stability on dynamic X-ray (motion between the adjacent spinous process $<2 \mathrm{~mm}$ ) was assessed for fusion status. The intervertebral disk space height (DSH) was calculated as the mean value of the anterior and posterior intervertebral disk heights as measured on plain lateral radiography. The measurements were performed by a single inde-
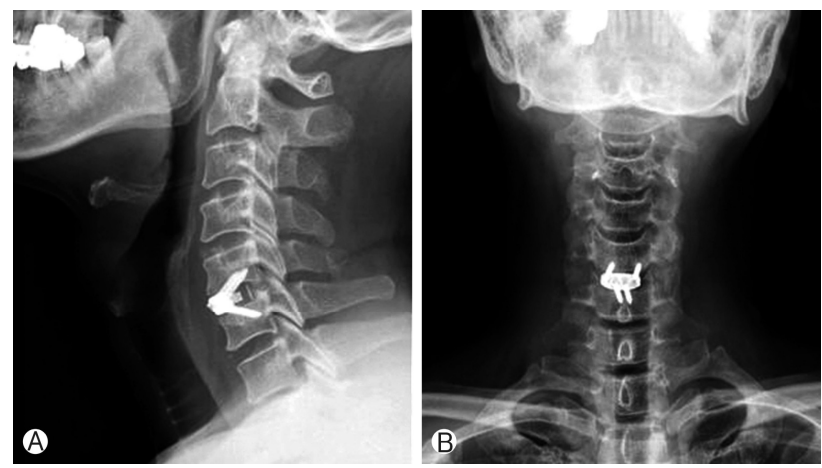

Fig. 1. Zero-P cage (Depuy-Synthes Spine Inc., Raynham, MA, USA) was ipacted with putty foam of CGDMB100 and inserted into the disc space under fluoroscopic guidance. (A) Lateral view of postoperative plain radiograph. (B) Anteropsterior view of postoperative plain radiograph.

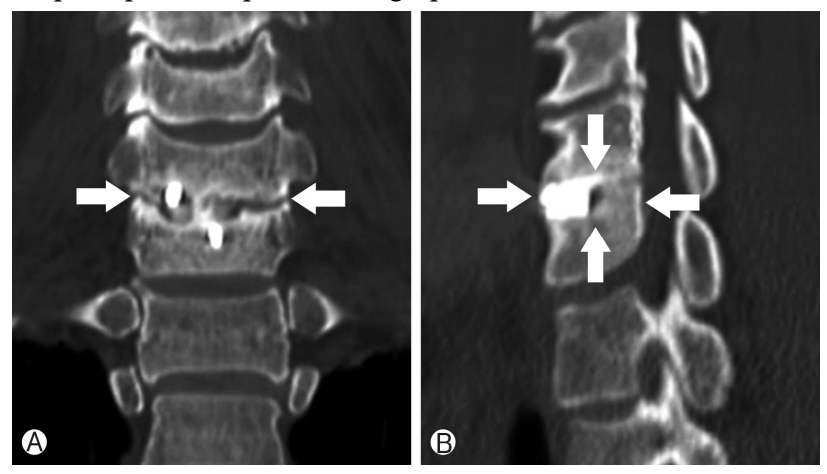

Fig. 2. Evaluation of bone fusion by "6-point scoring" system. Imaging studies of a patient with $\mathrm{C}^{-7} \mathrm{ACDF}$ with Zero-P stand- alone cage with CGDBM100 (solid fusion was achieved with 4-point by the system). Bone fusion check points (white arrow) represent bridging bone of 6 surfaces (anterior, posterior, superior, inferior and both lateral sides) around the graft. (A) Coronal reconstruction image from postoperative computed tomography (CT) scans representing bridging bone of both lateral surfaces. (B) Sagittal reconstruction images form the postoperative CT scans representing bridging bone of anterior, posterior, superior, and inferior surfaces. 
Chung $\mathrm{HJ}$ et al.

Table 2. Mean Values of clinical parameters

\begin{tabular}{lccccc}
\hline \hline Parameter & Preoperative & 1 Month & 3 Months & 6 Months & p-value \\
\hline VAS & $6.3 \pm 1.1$ & $3.1 \pm 2.1$ & $2.2 \pm 0.8$ & $1.3 \pm 1.4$ & $<0.05^{*}$ \\
ODI & $20.2 \pm 8.1$ & $7.6 \pm 5.7$ & $6.2 \pm 3.1$ & $4.1 \pm 3.4$ & $<0.05^{*}$ \\
NDI (\%) & $67.2 \pm 21.7$ & $35.5 \pm 18.4$ & $32.1 \pm 9.8$ & $21.9 \pm 11.3$ & $<0.05^{*}$ \\
SF-36 (\%) & $30.4 \pm 6.6$ & $51.4 \pm 8.5$ & $58.2 \pm 11.3$ & $60.6 \pm 13.2$ & $<0.05^{*}$ \\
\hline
\end{tabular}

Values are presented as mean \pm standard deviation.

VAS, visual analogue scale; ODI, Owestry disability index; NDI, neck disability index; SF-36, short-from health survey questionnaire-36.

"Comparison of preoperative and last follow-up mean values.

pendent observer who was not involved in the surgery or care of the patients.

Clinical efficacy was evaluated using visual analogue scale (VAS) score, Owestry disability index (ODI), neck disability index, and short-form health questionnaire-36 (SF-36) at 1, 3, and 6-month follow-up visits. The safety of the bone graft substitute was assessed with vital sign monitoring and a survey regarding complications at each follow-up visit.

Data were analyzed using the SPSS ver. 12.0 (SPSS Inc., Chicago, IL, USA); the paired Student t-test was used for the analyses. Data are presented as the mean with standard deviation. For all analyses, $\mathrm{p}<0.05$ was considered statistically significant.

This study was approved by a Catholic Medical College Cinical Research Coordinating Center (CMC CRCC) (approval number: KIRB-00355_31-002)

\section{RESULTS}

The intraoperative data are shown in Table 1 . The mean duration of the operation was $63 \pm 14$ minutes and mean intraoperative blood loss was $41 \pm 23 \mathrm{~mL}$. There were no surgeryrelated complications such as hoarseness, dysphagia, or hematoma in any patients.

There were significant improvements in VAS and ODI scores after a mean 6 months of follow-up. The mean VAS score decreased from $6.3 \pm 1.1$ to $1.3 \pm 1.4$ and the mean ODI score decreased from $20.2 \pm 8.2$ to $4.1 \pm 3.4$ ( $p<0.05$ preoperative vs. final follow-up). The mean neck disability index score decreased significantly at the first 3 months after surgery and remained steady until 6 months postoperatively. Quality of life was notably improved, as the mean SF-36 score went from 30.4\% before surgery to $60.6 \%$ at the last follow-up. A summary of the clinical data is shown in Table 2. Neurologic deterioration related to the fusion segment was not observed in any patients.

In all patients, stability of the graft was confirmed by plain radiograph and CT scan at 1,3 , and 6 months after surgery. At 6 months after the surgery, solid fusion was achieved in all patients as evidenced by formation of bridging bone on the surface of the graft on CT scans. The mean score in the 6-point scoring system was 4.3 and bony formation achieved at least 4 point in all patients. Six of 20 fusion levels (30\%) showed 5- to 6-point fusion (Table 3 ). In addition, no mobility was
Table 3. Results of bone fusion by 6-point scoring system

\begin{tabular}{lc}
\hline \multicolumn{1}{c}{ Score } & No. of levels $(\%)$ \\
\hline 6 Point & $1(5)$ \\
5 Point & $5(25)$ \\
4 Point & $14(70)$ \\
Mean point score & 4.3 \\
\hline
\end{tabular}

observed on the dynamic radiograph in any operated segment. When the clinical outcome parameters were compared between the point groups, there were no significant statistical differences.

Intervertebral DSH was significantly improved after surgery and well maintained over the next 6 months. The mean preoperative DSH was $3.5 \pm 1.2 \mathrm{~mm}$. The mean DSH at 1 month after surgery was $7.2 \pm 0.9 \mathrm{~mm}$; at the final follow-up it was $6.9 \pm 1.8 \mathrm{~mm}(\mathrm{p}<0.05$ before surgery vs. after surgery, $\mathrm{p}<0.05$ before surgery vs. final follow-up).

There was no case of implant-related complications such as dysphagia, cage failure, or migration, and there were no compli cations associated with the use of CGDBM100 during the follow-up period.

\section{DISCUSSION}

ACDF surgery is a well-established gold standard treatment for cervical degenerative disease. Solid bony fusion is essential for positive outcomes following ACDF surgery as it prevents foraminal stenosis and late angulation deformity ${ }^{22,40)}$. However, the choice of optimal fusion material is still controversial; various fusion materials have been claimed to promote superior outcomes ${ }^{27)}$. In this study, we attempted to analyze the clinical and radiologic efficacy of DBM as a stand-alone fusion material in single-level ACDF surgery.

Although use of an autograft harvested from the iliac crest as an interbody fusion material provides satisfactory clinical results and fusion rates, the rate of donor-site morbidity has been reported to be as high as $20 \%$ to $30 \%$ and can often reduce patient satisfaction and quality of life ${ }^{9,11,14,22,28)}$. Various materials have been proposed as interbody grafts for ACDF surgery to avoid the problems associated with autologous bone grafts ${ }^{12,20,43,45)}$. The characteristics of an ideal graft material include immediate structural biomechanical stability and the capacity for sub- 
sequent osteogenesis ${ }^{15,28,35)}$. Titanium, carbon fiber, and PEEK are the most commonly used materials for cervical interbody cages. A titanium cage may lead to vertebral body collapse if the end plate is damaged during discectomy and has been associated with high degree of subsidence ${ }^{29,37}$. Moreover, radiological metallic artifacts may complicate postoperative radiologic imaging. Transparent carbon fiber cages have been used widely, but a high rate of pseudoarthrosis, unexpected local connective tissue formation, and a risk of systemic uptake have frequently been reported ${ }^{4,30}$.

In most prior studies on allograft fusion materials, a cage packed with allogeneic cancellous bone chips was used to avoid donor-site complications ${ }^{1,7,41)}$. We used DBM as a stand-alone graft material and packed the PEEK cage for maximal contact with a prepared endplate on either side of the cage. DBM has been demonstrated to have both osteoinductive and osteoconductive properties $^{21)}$. The principal components of DBM are BMPs, which are responsible for its osteoinductive activity, and the organic portions of bone, such as collagen, provide osteoconductive activity ${ }^{46}$. Recent studies advocate the use of DBM as a potential graft substitute or enhancer, but there was no prior clinical evidence to support its use as a stand-alone graft material. Moreover, DMB must be used in combination with other types of grafts because of its amorphous consistency; many spine surgeons prefer structural graft materials ${ }^{46}$.

There have been a few clinical trials on DBM as a fusion material in ACDF surgery ${ }^{13,23,32,33,47,49)}$. One of the first reports, a 2-center prospective randomized controlled clinical trial comparing allograft mixed with DBM and iliac crest autograft, showed no significant difference in the rate of pseudoarthosis $^{47}$. However, graft collapse was significantly more likely in the allograft-DBM group and the authors suggested the use of an autograft for better outcomes. In another level 3 study comparing the use of PEEK cages packed with morphogenic protein-2 (rhBMP-2) against allograft spacers with DBM, there was no significant difference in clinical outcomes or fusion rates between the two groups ${ }^{32}$. The DBM group demonstrated a significantly lower rate of postoperative swallowing difficulty, and the cost of implants was more than three times greater in the rhBMP-2 group. Those authors advocated the use of DBM over rhBMP-2 for anterior cervical fusion. Another four studies investigated the use of PEEK cages and DBM (Grafton, Medtronic Sofamor Danek USA, Inc., Memphis, MN, USA) in patients undergoing ACDF surgery ${ }^{13,23,33,49}$. The authors advocated the use of PEEK cages packed with DBM as interbody fusion materials for the treatment of degenerative cervical diseases, as satisfactory fusion rates and clinical results were achieved in long-term follow-ups.

In the present study, the fusion rate of ACDF surgery using DBM alone as a fusion material was comparable with that of published results of ACDF using an autologous bone graft. The PEEK cage provides immediate structural support and its hollow center allows a graft-host interface that facilitates adequate bone fusion ${ }^{28)}$. We experienced excellent short-term clinical outcomes and high patient satisfaction with the elimination of donor-site morbidity and anterior plating. No cage- or graft material-related complications were encountered, and DSH was well-preserved during the follow-up period. Therefore, the results of present study suggest that use of a stand-alone cage packed with DBM in ACDF surgery is a safe and effective alter native to conventional autologous iliac bone grafts.

In the present study, stand-alone PEEK cages were used in all operations. PEEK is a semicrystalline polyaromatic linear polymer that provides a good combination of strength, stiffness, toughness, and environmental resistance with biocompatible, nonabsorbable, and corrosion-resistant abilities ${ }^{13,25,52,56}$. Furthermore, the cage structure, which consists of (1) 2 titanium spikes on the upper and lower frames anchoring the vertebral body, providing immediate solid fixation, and (2) 4 holes with screw treads for screw fixation, 2 inferior medial ones and 2 lateral ones, giving passages for cranial screws, offers a fixation mechanism similar to that of an anterior plate and screw system $^{13)}$. In addition, the PEEK cage is radiolucent and does not produce an imaging artifact, which enables convenient evaluation of fusion status ${ }^{10,13)}$.

Cervical interbody cages have been developed to provide immediate stability and high fusion rates with and without supplemental fixation. Augmentation with plate fixation may seem preferable owing to higher fusion and lower reoperation rates and better pain relief ${ }^{8,17,22,44)}$. In spite of these benefits, anterior plating is associated with a morbidity rate of $2.2 \%$ to $24.0 \%$ according to previously published literature ${ }^{24,36}$. Complications include screw pullout, screw breakage, injury to neurovascular structures, injury to the esophagus, prolonged dysphagia, and wound infection ${ }^{6,16,38,48,55)}$. Additionally, the operative time is usually longer because of the need for additional retraction to apply the anterior plate and the asymmetry of the anterior cervical surface, which is related to the presence of osteophyte secondary to degenerative changes ${ }^{48)}$. In contrast to plate fixation, stand-alone cages are recessed below the margin of the anterior verterbral body, providing no-profile internal fixation, which avoids such complications ${ }^{2)}$. Moreover, stand-alone cages possess the advantage of a reduced risk of adjacent level degeneration and spondylotic changes ${ }^{31,34,53)}$.

Many studies on ACDF using stand-alone cages have demonstrated a high rate of cage subsidence resulting in sagittal imbalance and segmental height loss ${ }^{3,5,18}$. However, using a zeroprofile PEEK cage with additional screw augmentation, we did not observe any cage relate-complications. Moreover, our study showed that the DSH of the index level was significantly improved postoperatively and well-preserved during the followup period.

This study has several limitations, including a small number of study subjects, nonrandomized case selection, and a relatively short follow-up duration. Although well-designed randomized controlled studies with comparison groups are required for confirmation, our results suggest that stand-alone PEEK cages packed with DBM are a promising alternative fusion material for patients undergoing ACDF surgery. 


\section{CONCLUSION}

ACDF using DBM as a stand-alone graft material demonstrated good clinical and radiologic outcomes at a minimum 6month follow-up. The fusion rate was comparable to that of published results on traditional ACDF surgery using tricortical iliac crest grafts. With the use of the stand-alone cage and DBM, donor-site morbidity is eliminated, resulting in reduced postoperative pain. Therefore, the results of this study suggest that the use of DBM alone in ACDF surgery is a safe and effec tive alternative to the gold standard of autologous iliac bone graft.

\section{CONFLCT OF INTEREST}

No potential conflict of interest relevant to this article was reported.

\section{REFERENCES}

1. An HS, Simpson JM, Glover JM, Stephany J: Comparison between allograft plus demineralized bone matrix versus autograft in anterior cervical fusion. A prospective multicenter study. Spine (Phila Pa 1976) 20:2211-2216, 1995

2. Barbagallo GM, Romano D, Certo F, Milone P, Albanese V: Zero-P: a new zero-profile cage-plate device for single and multilevel ACDF. A single institution series with four years maximum follow-up and review of the literature on zero-profile devices. Eur Spine J 22 Suppl 6:S868-878, 2013

3. Barsa P, Suchomel P: Factors affecting sagittal malalignment due to cage subsidence in standalone cage assisted anterior cervical fusion. Eur Spine J 16:1395-1400, 2007

4. Bartels RH, Donk R, van Azn RD: Height of cervical foramina after anterior discectomy and implantation of a carbon fiber cage. J Neurosurg 95(1 Suppl):40-42, 2001

5. Bartels RH, Donk RD, Feuth T: Subsidence of stand-alone cervical carbon fiber cages. Neurosurgery 58:502-508, 2006

6. Bazaz R, Lee MJ, Yoo JU: Incidence of dysphagia after anterior cervical spine surgery: a prospective study. Spine (Phila Pa 1976) 27:2453-2458, 2002

7. Bishop RC, Moore KA, Hadley MN: Anterior cervical interbody fusion using autogeneic and allogeneic bone graft substrate: a prospective comparative analysis. J Neurosurg 85:206-210, 1996

8. Böhler J, Gaudernak T: Anterior plate stabilization for fracturedislocations of the lower cervical spine. J Trauma 20:203-205, 1980

9. Cauthen JC, Kinard RE, Vogler JB, Jackson DE, DePaz OB, Hunter OL, et al: Outcome analysis of noninstrumented anterior cervical discectomy and interbody fusion in 348 patients. Spine (Phila Pa 1976) 23:188-192, 1998

10. Cho DY, Liau WR, Lee WY, Liu JT, Chiu CL, Sheu PC: Preliminary experience using a polyetheretherketone (PEEK) cage in the treatment of cervical disc disease. Neurosurgery 51:13431349, 2002

11. Connolly PJ, Esses SI, Kostuik JP: Anterior cervical fusion: outcome analysis of patients fused with and without anterior cervical plates. J Spinal Disord 9:202-206, 1996

12. Cook SD, Dalton JE, Tan EH, Tejeiro WV, Young MJ, White- cloud TS 3rd: In vivo evaluation of anterior cervical fusions with hydroxylapatite graft material. Spine (Phila Pa 1976) 19: 1856-1866, 1994

13. Demircan MN, Kutlay AM, Colak A, Kaya S, Tekin T, Kibici $\mathrm{K}$, et al: Multilevel cervical fusion without plates, screws or autogenous iliac crest bone graft. J Clin Neurosci 14:723-728, 2007

14. Fielding JW: Complications of anterior cervical disk removal and fusion. Clin Orthop Relat Res (284):10-13, 1992

15. Floyd T, Ohnmeiss D: A meta-analysis of autograft versus allograft in anterior cervical fusion. Eur Spine J 9:398-403, 2000

16. Fountas KN, Kapsalaki EZ, Nikolakakos LG, Smisson HF, Johnston KW, Grigorian AA, et al: Anterior cervical discectomy and fusion associated complications. Spine (Phila Pa 1976) 32:23102317, 2007

17. Fraser JF, Härtl R: Anterior approaches to fusion of the cervical spine: a metaanalysis of fusion rates. J Neurosurg Spine 6:298303, 2007

18. Gercek E, Arlet V, Delisle J, Marchesi D: Subsidence of standalone cervical cages in anterior interbody fusion: warning. Eur Spine J 12:513-516, 2003

19. Goldberg VM, Stevenson S: Natural history of autografts and allografts. Clin Orthop Relat Res (225):7-16, 1987

20. Hacker RJ, Cauthen JC, Gilbert TJ, Griffith SL: A prospective randomized multicenter clinical evaluation of an anterior cervical fusion cage. Spine (Phila Pa 1976) 25:2646-2654, 2000

21. Han B, Tang B, Nimni ME: Combined effects of phosphatidylcholine and demineralized bone matrix on bone induction. Connect Tissue Res 44:160-166, 2003

22. Kaiser MG, Haid RW Jr, Subach BR, Barnes B, Rodts GE Jr: Anterior cervical plating enhances arthrodesis after discectomy and fusion with cortical allograft. Neurosurgery 50:229-236, 2002

23. Kang J, An H, Hilibrand A, Yoon ST, Kavanagh E, Boden S: Grafton and local bone have comparable outcomes to iliac crest bone in instrumented single-level lumbar fusions. Spine (Phila Pa 1976) 37:1083-1091, 2012

24. Kasimatis GB, Panagiotopoulos E, Gliatis J, Tyllianakis M, Zouboulis P, Lambiris E: Complications of anterior surgery in cervical spine trauma: an overview. Clin Neurol Neurosurg 111:1827, 2009

25. Katzer A, Marquardt H, Westendorf J, Wening JV, von Foerster G: Polyetheretherketone--cytotoxicity and mutagenicity in vitro. Biomaterials 23:1749-1759, 2002

26. Kim SC, Kang SW, Kim SH, Cho KH, Kim SH: Clinical and radiological outcomes of anterior cervical interbody fusion using hydroxyapatite spacer. J Korean Neurosurg Soc 46:300-304, 2009

27. Kulkarni AG, Hee HT, Wong HK: Solis cage (PEEK) for anterior cervical fusion: preliminary radiological results with emphasis on fusion and subsidence. Spine J 7:205-209, 2007

28. Liao JC, Niu CC, Chen WJ, Chen LH: Polyetheretherketone (PEEK) cage filled with cancellous allograft in anterior cervical discectomy and fusion. Int Orthop 32:643-648, 2008

29. Lin CN, Wu YC, Wang NP, Howng SL: Preliminary experience with anterior interbody titanium cage fusion for treatment of cervical disc disease. Kaohsiung J Med Sci 19:208-216, 2003

30. Matge G: Anterior interbody fusion with the BAK-cage in cervical spondylosis. Acta Neurochir (Wien) 140:1-8, 1998 
31. Miao J, Shen Y, Kuang Y, Yang L, Wang X, Chen Y, et al: Early follow-up outcomes of a new zero-profile implant used in anterior cervical discectomy and fusion. J Spinal Disord Tech 26: E193-197, 2013

32. Moon HJ, Kim JH, Kim JH, Kwon TH, Chung HS, Park YK: The effects of anterior cervical discectomy and fusion with standalone cages at two contiguous levels on cervical alignment and outcomes. Acta Neurochir (Wien) 153:559-565, 2011

33. Park HW, Lee JK, Moon SJ, Seo SK, Lee JH, Kim SH: The efficacy of the synthetic interbody cage and Grafton for anterior cervical fusion. Spine (Phila Pa 1976) 34:E591-595, 2009

34. Park JB, Cho YS, Riew KD: Development of adjacent-level ossification in patients with an anterior cervical plate. J Bone Joint Surg Am 87:558-563, 2005

35. Park JH, Roh SW: Anterior cervical interbody fusion using polyetheretherketone cage filled with autologous and synthetic bone graft substrates for cervical spondylosis: comparative analysis between PolyBone ${ }^{\circledR}$ and iliac bone. Neurol Med Chir (Tokyo) 53:85-90, 2013

36. Pitzen TR, Chrobok J, Stulik J, Ruffing S, Drumm J, Sova L, et al: Implant complications, fusion, loss of lordosis, and outcome after anterior cervical plating with dynamic or rigid plates: two-year results of a multi-centric, randomized, controlled study. Spine (Phila Pa 1976) 34:641-646, 2009

37. Profeta G, de Falco R, Ianniciello G, Profeta L, Cigliano A, Raja AI: Preliminary experience with anterior cervical microdiscectomy and interbody titanium cage fusion (Novus CT-Ti) in patients with cervical disc disease. Surg Neurol 53:417-426, 2000

38. Riley LH 3rd, Skolasky RL, Albert TJ, Vaccaro AR, Heller JG: Dysphagia after anterior cervical decompression and fusion: prevalence and risk factors from a longitudinal cohort study. Spine (Phila Pa 1976) 30:2564-2569, 2005

39. Riley LH Jr, Robinson RA, Johnson KA, Walker AE: The results of anterior interbody fusion of the cervical spine. Review of ninety-three consecutive cases. J Neurosurg 30:127-133, 1969

40. Sampath P, Bendebba M, Davis JD, Ducker TB: Outcome of patients treated for cervical myelopathy. A prospective, multicenter study with independent clinical review. Spine (Phila Pa 1976) 25:670-676, 2000

41. Shad A, Leach JC, Teddy PJ, Cadoux-Hudson TA: Use of the Solis cage and local autologous bone graft for anterior cervical discectomy and fusion: early technical experience. J Neurosurg Spine 2:116-122, 2005

42. Shin JS, Oh SH, Cho PG: Surgical outcome of a Zero-profile Device comparing with stand-alone cage and anterior cervical plate with iliac bone graft in the anterior cervical discectomy and fusion. Korean J Spine 11:169-177, 2014

43. Shono Y, McAfee PC, Cunningham BW, Brantigan JW: A biome- chanical analysis of decompression and reconstruction methods in the cervical spine. Emphasis on a carbon-fiber-composite cage. J Bone Joint Surg Am 75:1674-1684, 1993

44. Song KJ, Taghavi CE, Lee KB, Song JH, Eun JP: The efficacy of plate construct augmentation versus cage alone in anterior cervical fusion. Spine (Phila Pa 1976) 34:2886-2892, 2009

45. Steffen T, Tsantrizos A, Fruth I, Aebi M: Cages: designs and concepts. Eur Spine J 9 Suppl 1:S89-94, 2000

46. Tilkeridis K, Touzopoulos P, Ververidis A, Christodoulou S, Kazakos K, Drosos GI: Use of demineralized bone matrix in spinal fusion. World J Orthop 5:30-37, 2014

47. Topuz K, Colak A, Kaya S, Simşek H, Kutlay M, Demircan $\mathrm{MN}$, et al: Two-level contiguous cervical disc disease treated with peek cages packed with demineralized bone matrix: results of 3-year follow-up. Eur Spine J 18:238-243, 2009

48. Tortolani PJ, Cunningham BW, Vigna F, Hu N, Zorn CM, McAfee PC: A comparison of retraction pressure during anterior cervical plate surgery and cervical disc replacement: a cadaveric study. J Spinal Disord Tech 19:312-317, 2006

49. Vaccaro AR, Stubbs HA, Block JE: Demineralized bone matrix composite grafting for posterolateral spinal fusion. Orthopedics 30:567-570, 2007

50. Wang JC, Alanay A, Mark D, Kanim LE, Campbell PA, Dawson EG, et al: A comparison of commercially available demineralized bone matrix for spinal fusion. Eur Spine J 16:1233-1240, 2007

51. Wang JC, McDonough PW, Kanim LE, Endow KK, Delamarter RB: Increased fusion rates with cervical plating for three-level anterior cervical discectomy and fusion. Spine (Phila Pa 1976) 26:643-646, 2001

52. Wenz LM, Merritt K, Brown SA, Moet A, Steffee AD: In vitro biocompatibility of polyetheretherketone and polysulfone composites. J Biomed Mater Res 24:207-215, 1990

53. Yang JY, Song HS, Lee M, Bohlman HH, Riew KD: Adjacent level ossification development after anterior cervical fusion without plate fixation. Spine (Phila Pa 1976) 34:30-33, 2009

54. Yue WM, Brodner W, Highland TR: Long-term results after anterior cervical discectomy and fusion with allograft and plating: a 5- to 11-year radiologic and clinical follow-up study. Spine (Phila Pa 1976) 30:2138-2144, 2005

55. Yue WM, Brodner W, Highland TR: Persistent swallowing and voice problems after anterior cervical discectomy and fusion with allograft and plating: a 5- to 11-year follow-up study. Eur Spine J 14:677-682, 2005

56. Zdeblick TA, Ducker TB: The use of freeze-dried allograft bone for anterior cervical fusions. Spine (Phila Pa 1976) 16:726-729, 1991 